\section{Pacific Northwest}

National Laboratory

Operated by Battelle for the

U.S. Department of Energy

\title{
Composite Load Model Evaluation
}

N. Lu

A. Qiao

September 2007

Prepared for the Bonneville Power Administration Under contract, 00162-00033

With the U.S. Department of Energy

Under DE-AC05-76RL01830 


\title{
DISCLAIMER
}

This report was prepared as an account of work sponsored by an agency of the United States Government. Neither the United States Government nor any agency thereof, nor Battelle Memorial Institute, nor any of their employees, makes any warranty, express or implied, or assumes any legal liability or responsibility for the accuracy, completeness, or usefulness of any information, apparatus, product, or process disclosed, or represents that its use would not infringe privately owned rights. Reference herein to any specific commercial product, process, or service by trade name, trademark, manufacturer, or otherwise does not necessarily constitute or imply its endorsement, recommendation, or favoring by the United States Government or any agency thereof, or Battelle Memorial Institute. The views and opinions of authors expressed herein do not necessarily state or reflect those of the United States Government or any agency thereof.

\author{
PACIFIC NORTHWEST NATIONAL LABORATORY \\ operated by \\ BATTELLE \\ for the \\ UNITED STATES DEPARTMENT OF ENERGY \\ under Contract DE-AC0576RL01830
}

Printed in the United States of America
Available to DOE and DOE contractors from the Office of Scientific and Technical Information,
P.O. Box 62, Oak Ridge, TN 37831-0062;
ph: (865) 576-8401
fax: (865) 576-5728
email: reports@adonis.osti.gov

\begin{abstract}
Available to the public from the National Technical Information Service, U.S. Department of Commerce, 5285 Port Royal Rd., Springfield, VA 22161 ph: (800) 553-6847 fax: (703) 605-6900

email: orders@ntis.fedworld.gov

online ordering: http://www.ntis.gov/ordering.htm
\end{abstract}

This document was printed on recycled paper.

$(8 / 00)$ 


\section{Composite Load Model Evaluation}

N. Lu

A. Qiao

September 2007

Prepared for the Bonneville Power Administration Under contract, 00162-00033

With the U.S. Department of Energy

Under DE-AC05-76RL01830

Pacific Northwest National Laboratory

Richland, Washington 99352 


\section{SUMMARY}

This final report is prepared for Bonneville Power Administration to document the methodology and procedure used to evaluate the new composite load model, CMPLDW, which is developed by GE Energy. The composite load model structure is provided by the WECC load modeling task force. It is to be used to represent behaviors of different end-user components. GE Energy has implemented this composite load model with a new function CMPLDW in its power system simulation software package, Positive Sequence Load Flow (PSLF). Pacific Northwest National Laboratory (PNNL) and BPA joined forces and conducted the evaluation of the CMPLDW and tested its parameter settings. The PNNL testing results are documented in this report. 


\section{Table of Contents}

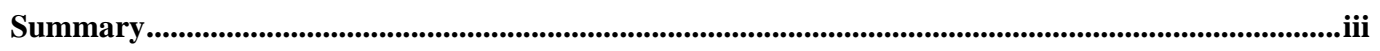

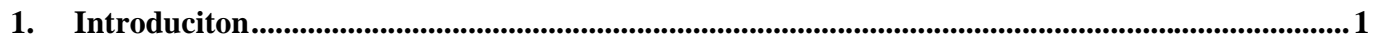

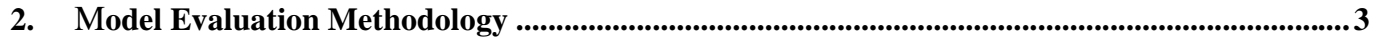

3. Evaluation Test Procedures and results..............................................................................................

3.1 Test 1: Compare Motor-W with CMPLDW …................................................................ 5

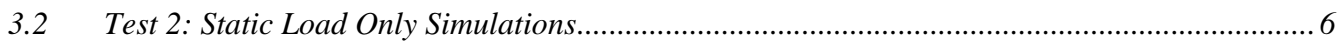

3.3 Test 3: Four Motor Loads .............................................................................................. 7

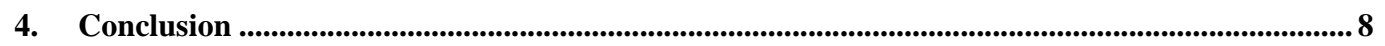

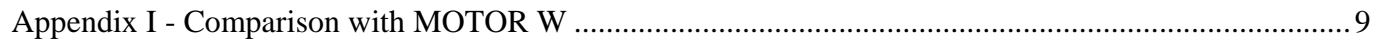

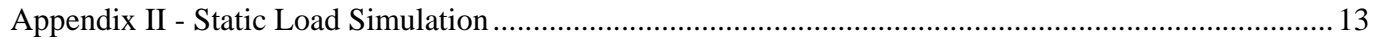

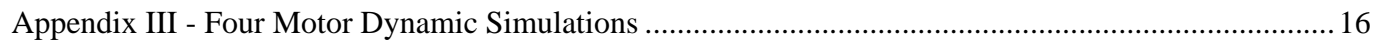

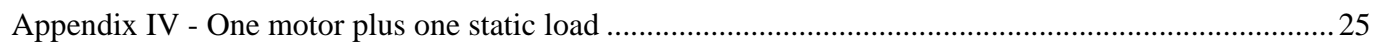

Appendix V - WECC Composite Load Model (CMPLDW) Specifications ............................................27 


\section{Figures}

Figure 1: The Composite Load Model Structure ...................................................................................... 1

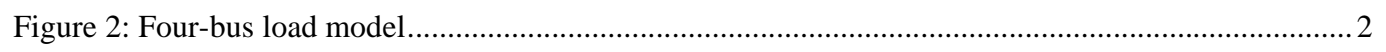

Figure 3: Sample testing signals (oscillation, voltage hump, voltage rampup and rampdown, and voltage

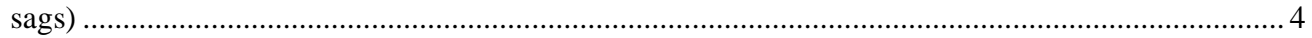

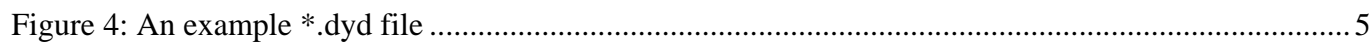

\section{Tables}

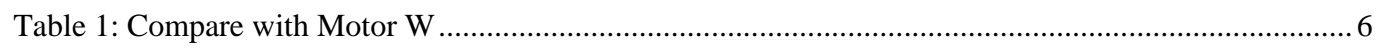

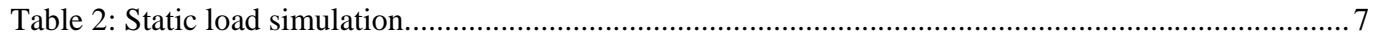

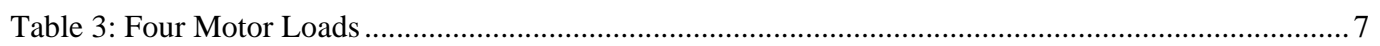




\section{INTRODUCITON}

The WECC load modeling task force has dedicated its effort in the past few years to developing a composite load model that can represent behaviors of different end-user components. The modeling structure of the composite load model recommended by the WECC load modeling task force has been illustrated in Figure 1. GE Energy has implemented this composite load model with a new function CMPLDW in its power system simulation software package, Positive Sequence Load Flow (PSLF).

For the last several years, Bonneville Power Administration (BPA) has taken the lead and collaborated with GE Energy to develop the new composite load model. Pacific Northwest National Laboratory (PNNL) and BPA joined forces and conducted the evaluation of the CMPLDW and tested its parameter settings to make sure that:

- $\quad$ the model initialized properly

- $\quad$ all the parameter settings were functioning

- $\quad$ the simulation results were as expected.

The PNNL effort focused on testing the CMPLDW in a four-bus system, as shown in Figure 2. Exhaustive testing on each parameter setting has been performed to guarantee each setting works. This report is a summary of the PNNL testing results and conclusions.

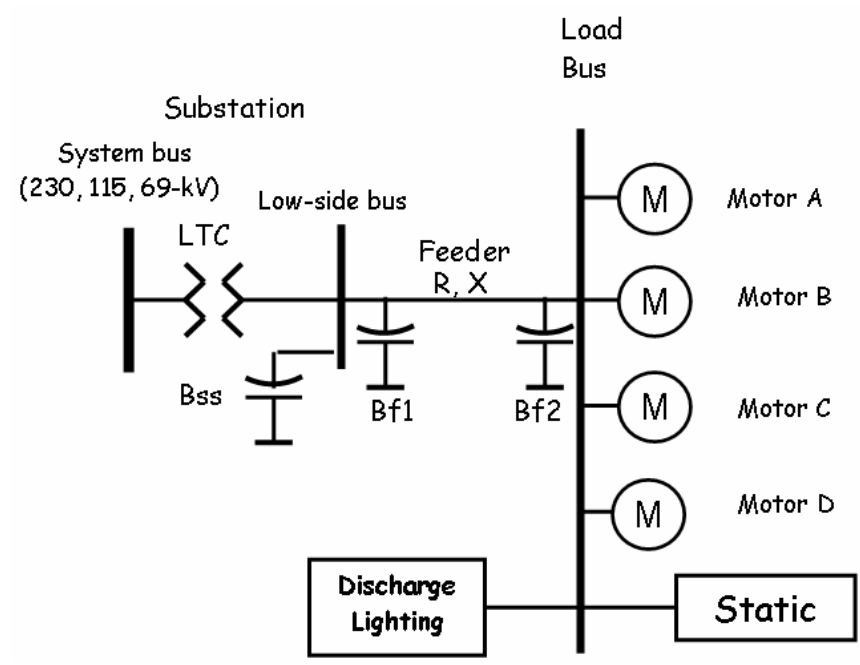

Figure 1: The Composite Load Model Structure 


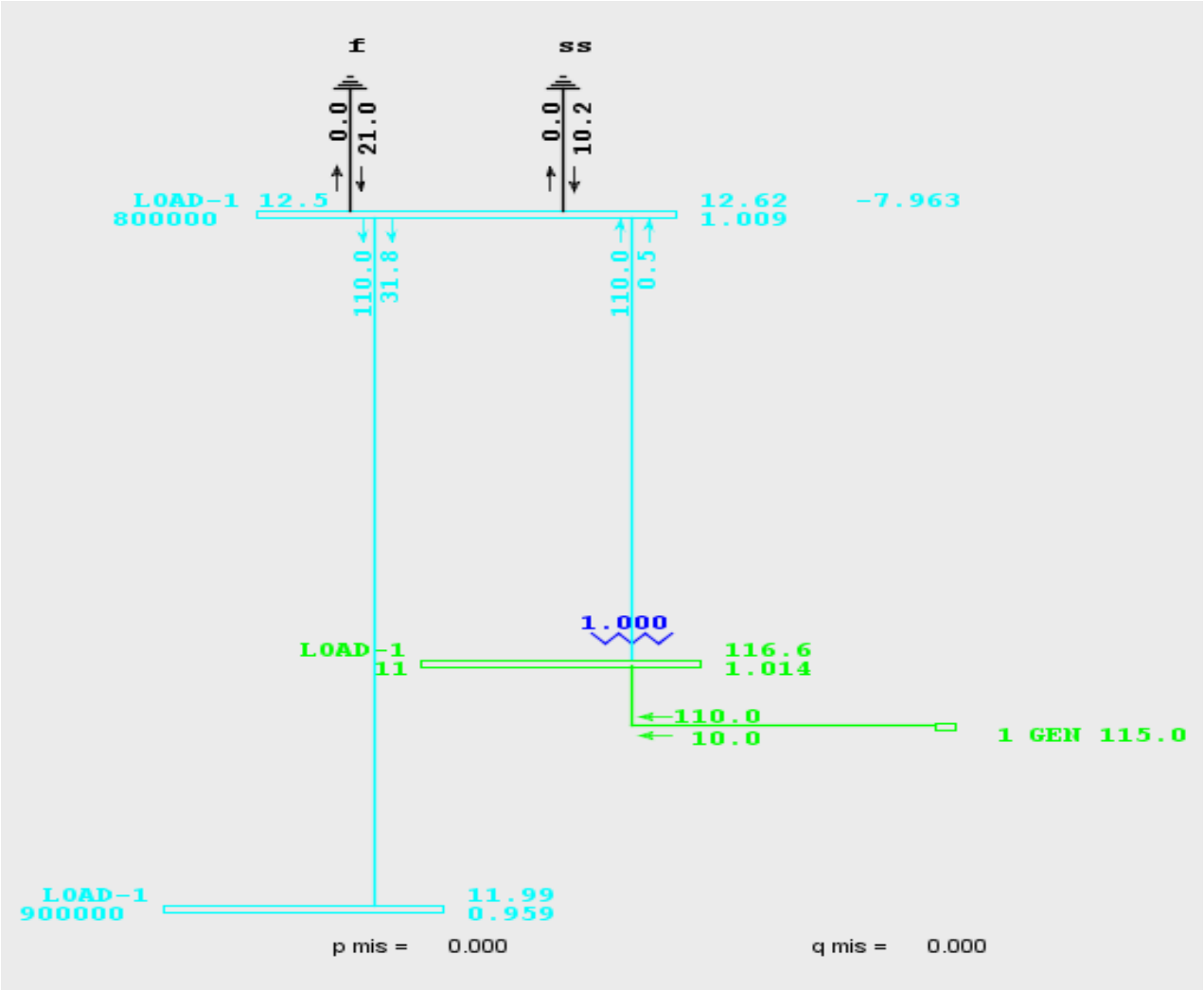

Figure 2: Four-bus load model 


\section{MODEL EVALUATION METHODOLOGY}

The most rigorous way to build confidence in models is to compare model simulation results with field measurements. However, because the CMPLDW model is built upon several known load models, PNNL's evaluation is, therefore, conducted by comparing the simulation results obtained by the validated model and the CMPLDW model.

1. Motor load modeling: Set the static load to zero and operate only one motor load. For example, Motor A is running and Motor B, C, and D are offline. Then, compare the simulation results obtained by CMPLDW with the results by Motor W.

2. Static load modeling: compare with the direct calculations.

3. Test each parameter setting: Exhaustive tests are run, in which only one parameter is changed at a time to observe the results.

Please refer to Appendix V of the GE Energy: WECC Composite Load Model (CMPLDW) Specifications for the parameter settings.

CSV files are used to create the testing signals. PSLF playback function is used to inject different testing signals as shown in Figure 3, which include:

- Voltage sags

- Voltage ramp

- Voltage oscillation

- Voltage hump

- Frequency sag

- Frequency oscillation

- Frequency ramp 

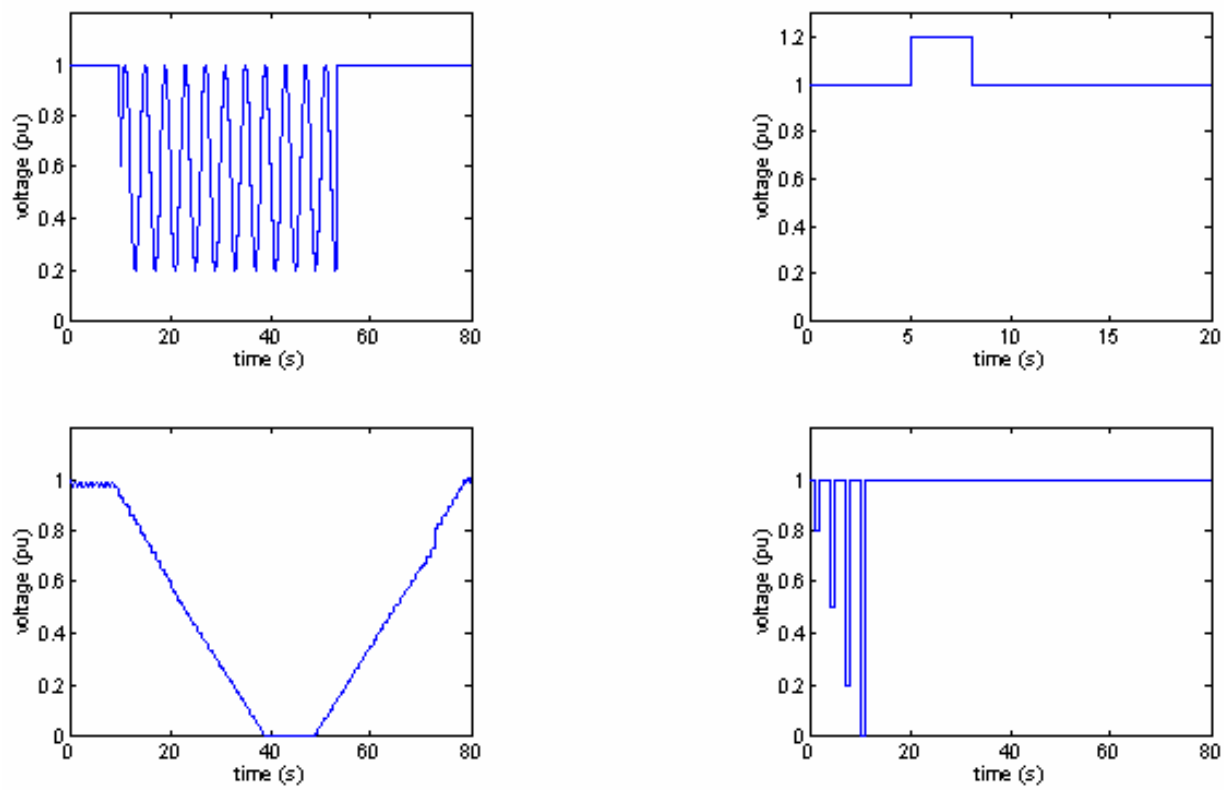

Figure 3: Sample testing signals (oscillation, voltage hump, voltage rampup and rampdown, and voltage sags)

To summarize, the CLM settings tested are:

- Compared with Motor W

- Static load only

- Four motor loads

- Partial tripping settings: Vtr1, Ftr1, Vtr2, Ftr2

- Load torque settings: etrq

- H settings

- Different motor parameters: big industrial load, small industrial load, compressor loads

- Static load plus one motor load

As a result of the overwhelming figures created from the test data, only a selected few are presented in Appendices I through IV. If the results are as expected, the test was considered "passed". 


\section{EVALUATION TEST PROCEDURES AND RESULTS}

\subsection{Test 1: Compare Motor W with CMPLDW}

In this test, all the motor parameters were set equal. The fraction of the motor load fraction to be "Fma" 1.0 "Fmb" 0.0 "Fmc" 0.0 "Fmd" $\quad 0.0$ "Fdl" 0.0 /, or "Fma" $\quad 0.0$ "Fmb" 1.0 "Fmc" 0.0 "Fmd" 0.0 "Fdl" 0.0 /, or "Fma" $\quad 0.0$ "Fmb" 0.0 "Fmc" 1.0 "Fmd" 0.0 "Fdl" 0.0 /, or "Fma" $\quad 0.0$ "Fmb" 0.0 "Fmc" 0.0 "Fmd" 1.0 "Fdl" 0.0 /. An example of the *.dyd files is shown in Figure 4.

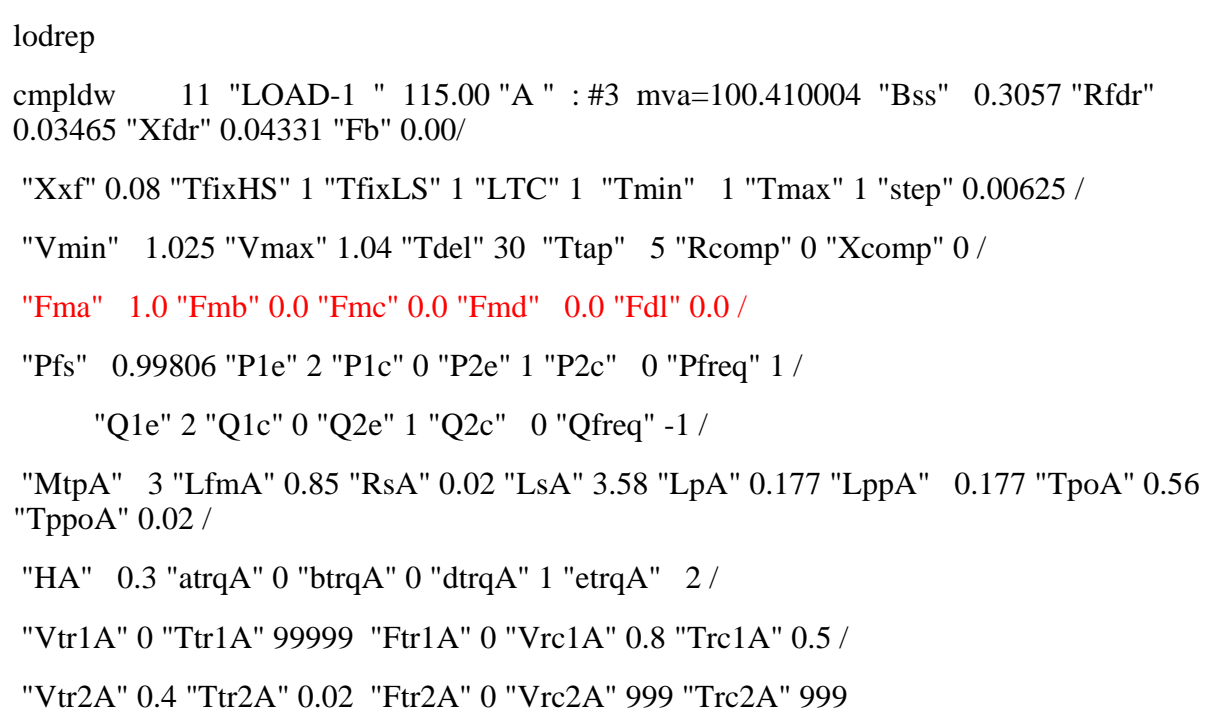

Figure 4: An example *.dyd file

The following scenarios were tested and results are included in Appendix I and also summarized in Table 1. 
Table 1: Compare with Motor W

\begin{tabular}{|l|l|l|}
\hline Scenarios & Pass & $\begin{array}{l}\text { Not } \\
\text { pass }\end{array}$ \\
\hline Voltage Sags & $\checkmark$ & \\
\hline Voltage Ramp & $\checkmark$ & \\
\hline Voltage Oscillation & $\checkmark$ & \\
\hline Voltage Hump & $\checkmark$ & \\
\hline Frequency Sag & $\checkmark$ & \\
\hline Frequency Oscillation & $\checkmark$ & \\
\hline Frequency Ramp & $\checkmark$ & \\
\hline
\end{tabular}

\subsection{Test 2: Static Load Only Simulations}

$\mathrm{P}$ and $\mathrm{Q}$ of the static load model can be described in the following equations:

$$
\begin{gathered}
P=P_{0}\left(P 1 c\left(\frac{V}{V_{0}}\right)^{P 1 e}+P_{2 C}\left(\frac{V}{V_{0}}\right)^{P 2 e}+P 3\right)\left(1+p f^{*} \Delta f\right) \\
Q=Q_{0}\left(Q 1 c\left(\frac{V}{V_{0}}\right)^{Q 1 e}+Q_{2 C}\left(\frac{V}{V_{0}}\right)^{Q 2 e}+Q 3\right)\left(1+p f^{*} \Delta f\right)
\end{gathered}
$$

In the static load simulation, the motor fraction was set to zero,

"Fma" $0 \quad$ "Fmb" $0 \quad$ "Fmc" $0 \quad$ "Fmd" $0 \quad$ "Fdl" 1 / "Pfs" 0.96187

and three cases were analyzed. The simulation parameters and results are included in Appendix II and also summarized in Table 2. 
Table 2: Static load simulation

\begin{tabular}{|c|c|c|}
\hline Scenarios & Pass & $\begin{array}{l}\text { Not } \\
\text { pass }\end{array}$ \\
\hline $\begin{array}{ll}\text { CASE 1: } & \text { "P1e" } 2 \text { "P1c" } 0 \text { "P2e" } 1 \text { "P2c" } 1 \text { "Pfreq" } 0 \text { / } \\
& \text { "Q1e" } 2 \text { "Q1c" } 0 \text { "Q2e" } 1 \text { "Q2c" } 1 \text { "Qfreq" } 0 \text { / }\end{array}$ & $\checkmark$ & \\
\hline $\begin{array}{l}\text { "P1e" } 2 \text { "P1c" } 1 \text { "P2e" } 1 \text { "P2c" } 0 \text { "Pfreq" } 0 \text { / } \\
\text { "Q1e" } 2 \text { "Q1c" } 1 \text { "Q2e" } 1 \text { "Q2c" } 0 \text { "Qfreq" } 0\end{array}$ & $\checkmark$ & \\
\hline $\begin{array}{l}\text { CASE3 "P1e" } 2 \text { "P1c" } 0 \text { "P2e" } 1 \text { "P2c" } 0 \text { "Pfreq" } 0 \text { / } \\
\text { "Q1e" } 2 \text { "Q1c" } 0 \text { "Q2e" } 1 \text { "Q2c" } 0 \text { "Qfreq" } 0 \text { / }\end{array}$ & $\checkmark$ & \\
\hline
\end{tabular}

\subsection{Test 3: Four Motor Loads}

In the four motor dynamic simulations, the motor parameters of MA, Mb, MC and MD were varied one at a time, while the rest of the parameters remained the same. The simulation parameters and results are attached in Appendix III and also summarized in Table 3.

Table 3: Four Motor Loads

\begin{tabular}{|l|l|l|}
\hline Scenarios & Pass & $\begin{array}{l}\text { Not } \\
\text { pass }\end{array}$ \\
\hline Vary H, set etrq=0 & $\checkmark$ & \\
\hline Vary H, set etrq=2 & $\checkmark$ & \\
\hline Vary etrq & $\checkmark$ & \\
\hline Vary Rs & $\checkmark$ & \\
\hline Vary Fm & $\checkmark$ & \\
\hline Vary Vtr2 & $\checkmark$ & \\
\hline Vary Ftr2 & $\checkmark$ & \\
\hline Vary Vtr1, set Ttr1=2 & $\checkmark$ & \\
\hline
\end{tabular}




\section{CONCLUSION}

After extensive testing, the authors conclude that the CMPLDW model is correctly implemented and all the parameter settings are functioning properly. 
Appendix I - Comparison with MOTOR W 


\section{1 motor: Voltage Sags}

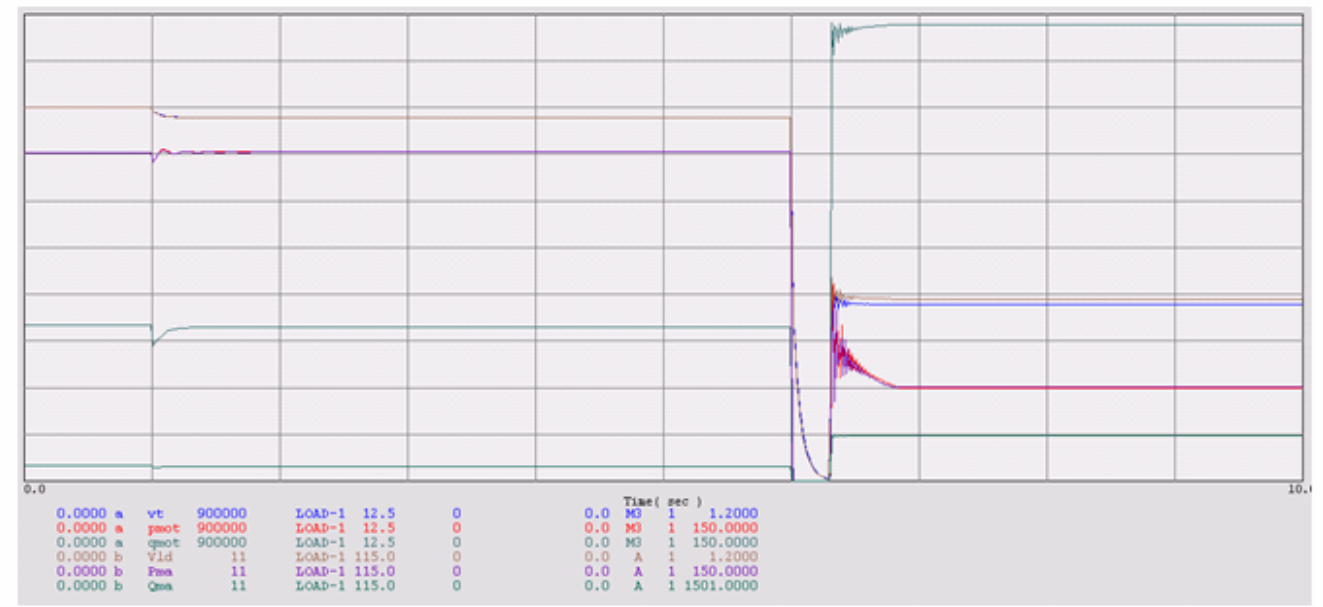

1 motor: Voltage Ramp

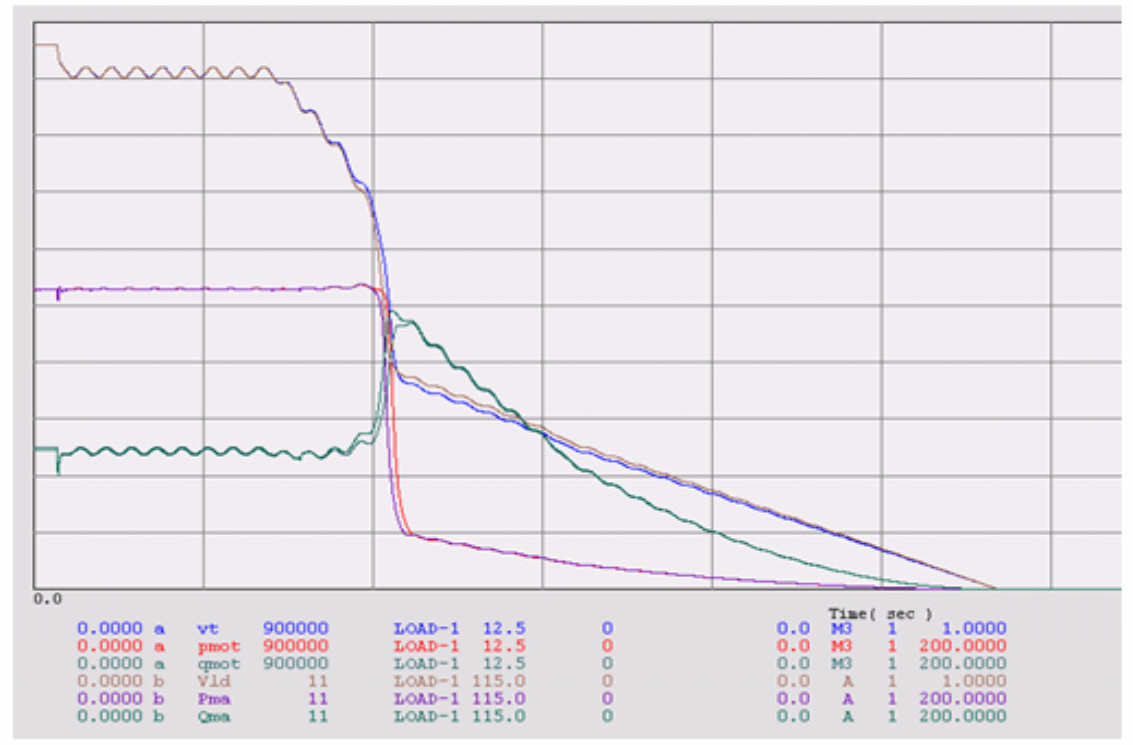




\section{1 motor: Voltage Oscillation}

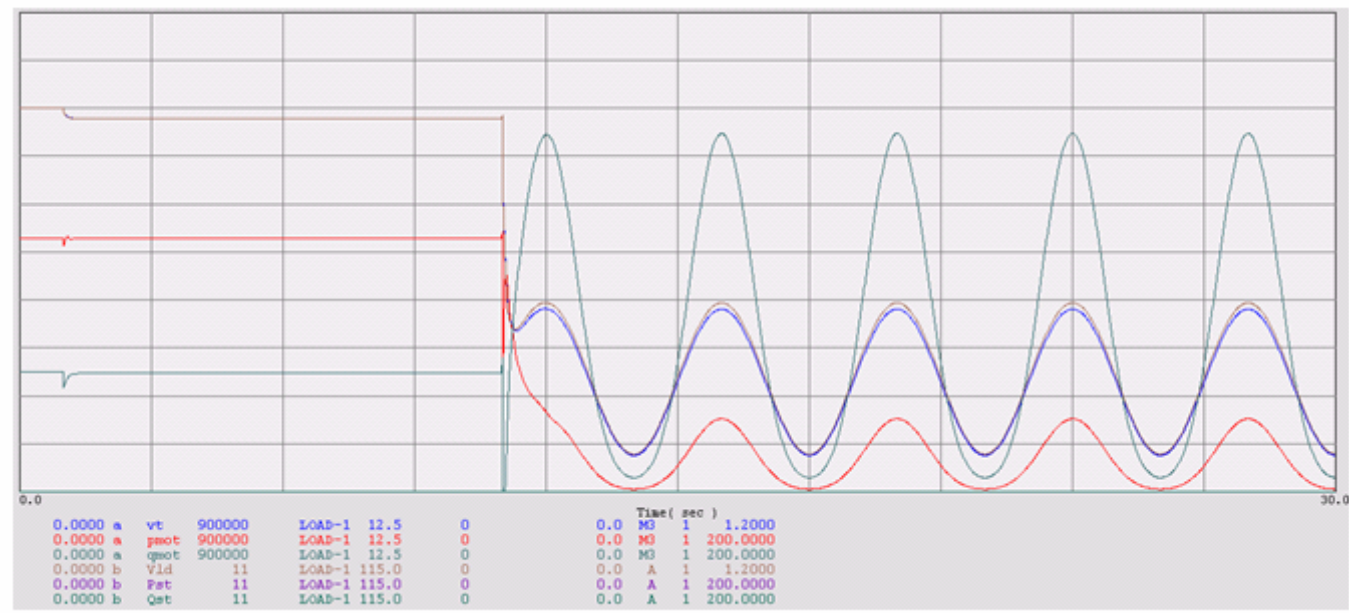

\section{1 motor: Frequency Oscillation}

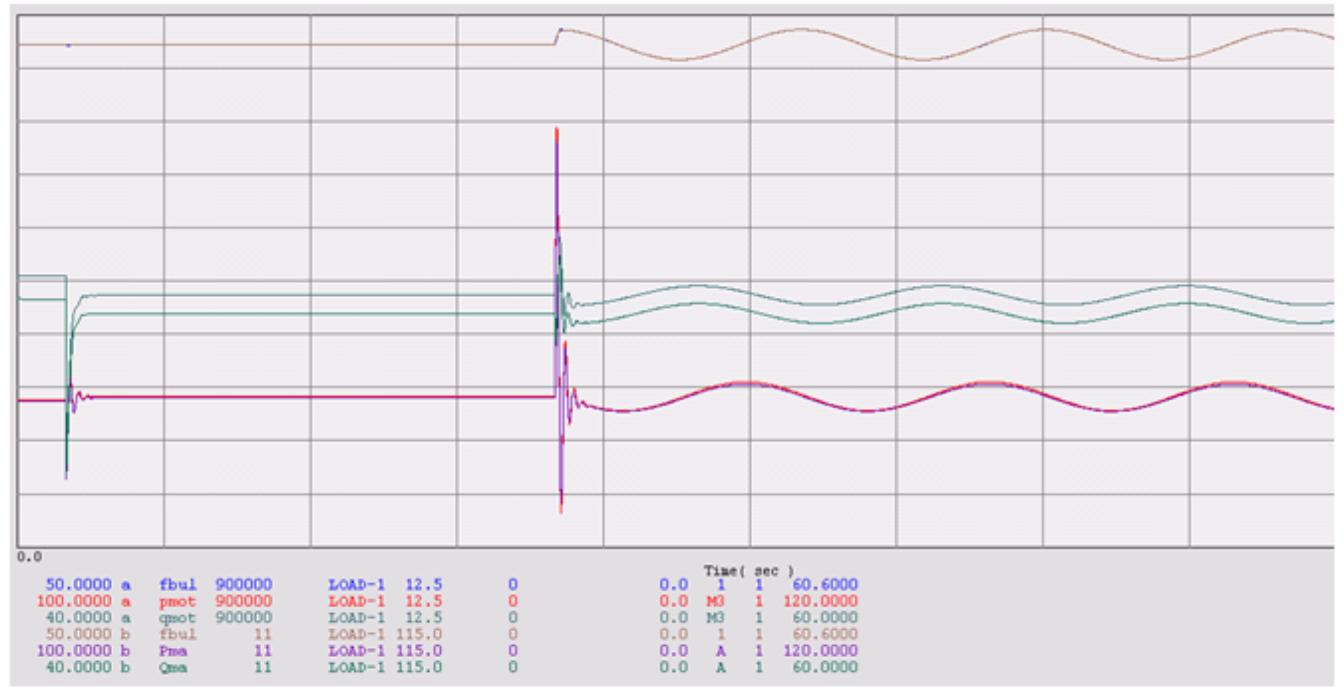




\section{1 motor: Frequency Sag}

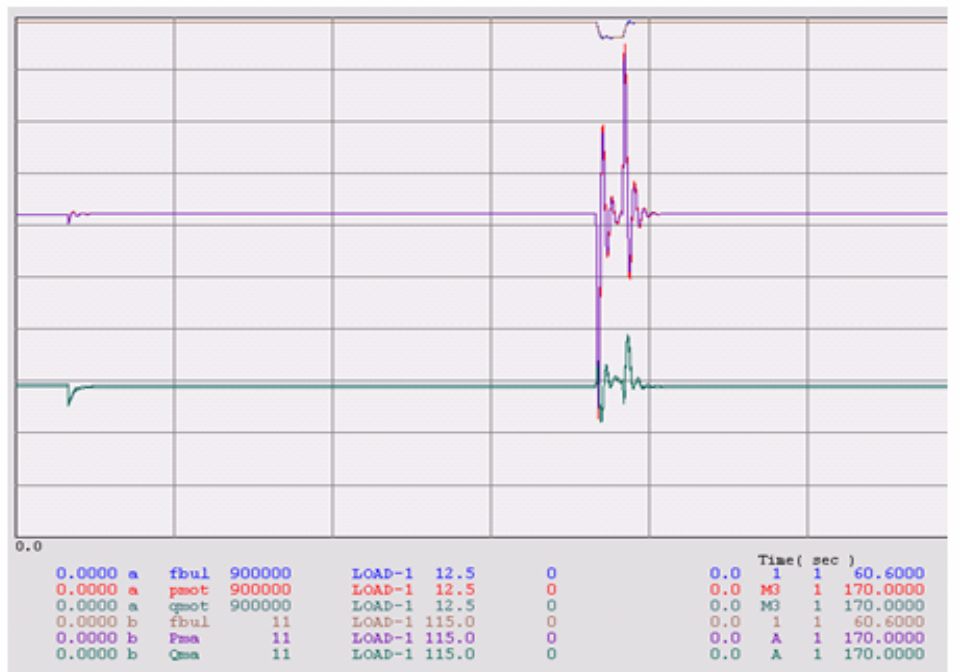

\section{1 motor: Frequency Ramp}

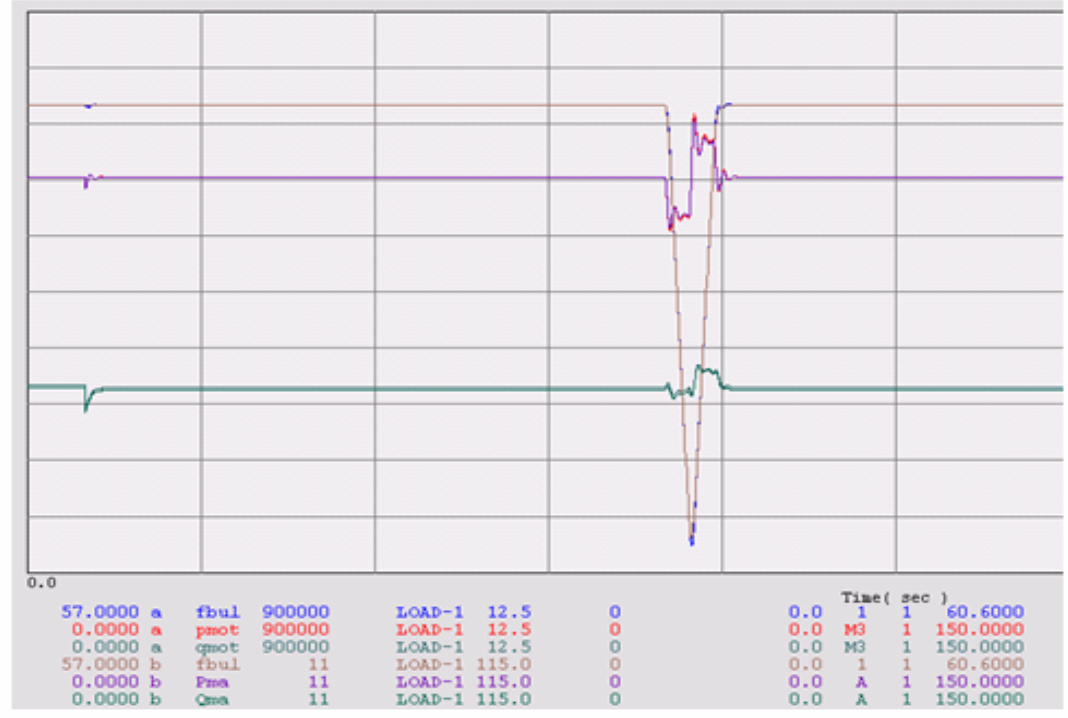


Appendix II - Static Load Simulation 


\section{Voltage rampdown and rampup}

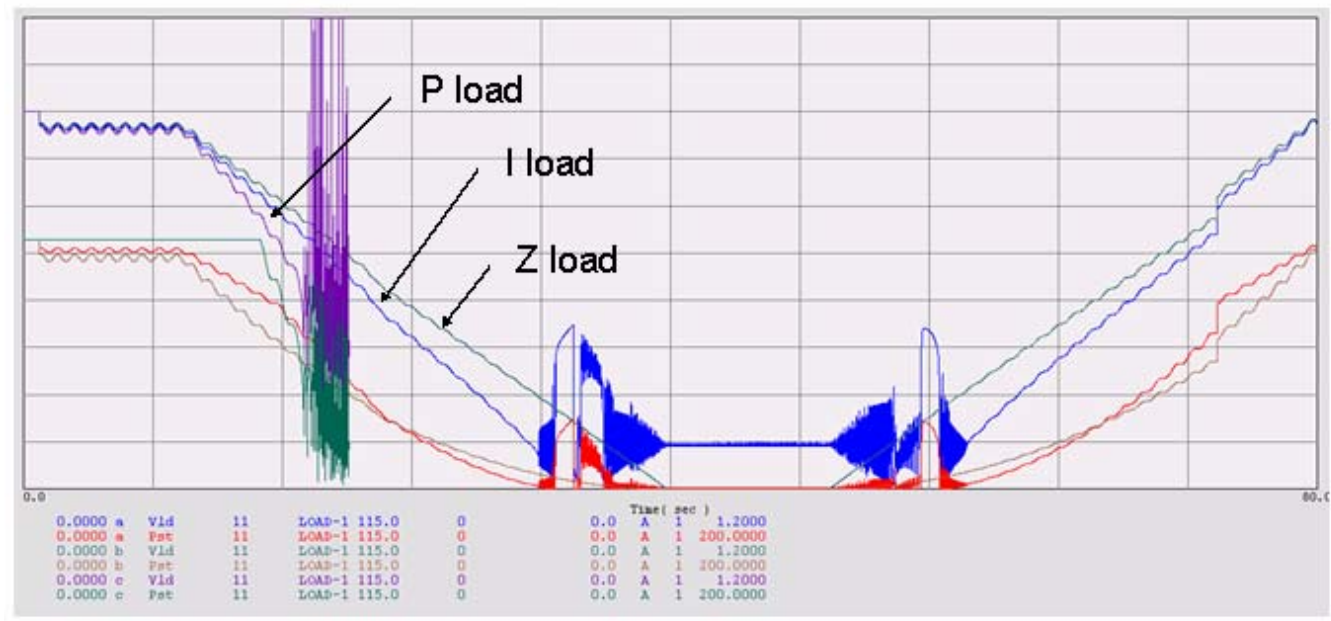

\section{Voltage sags}

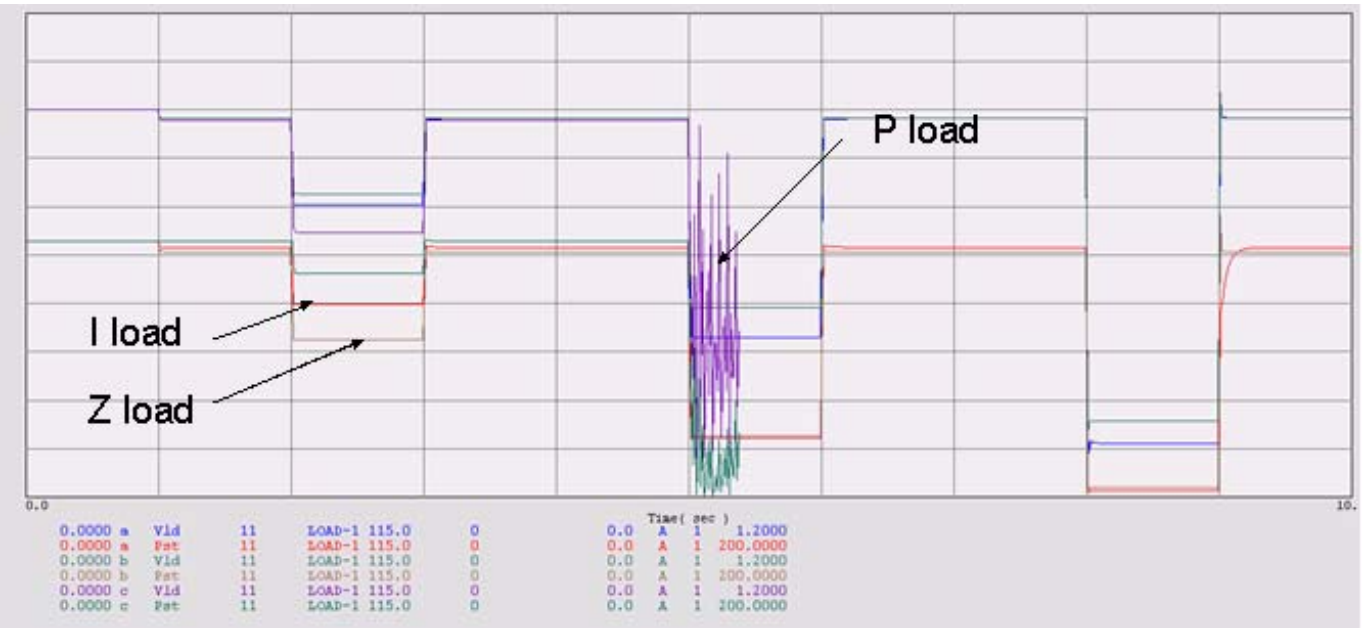




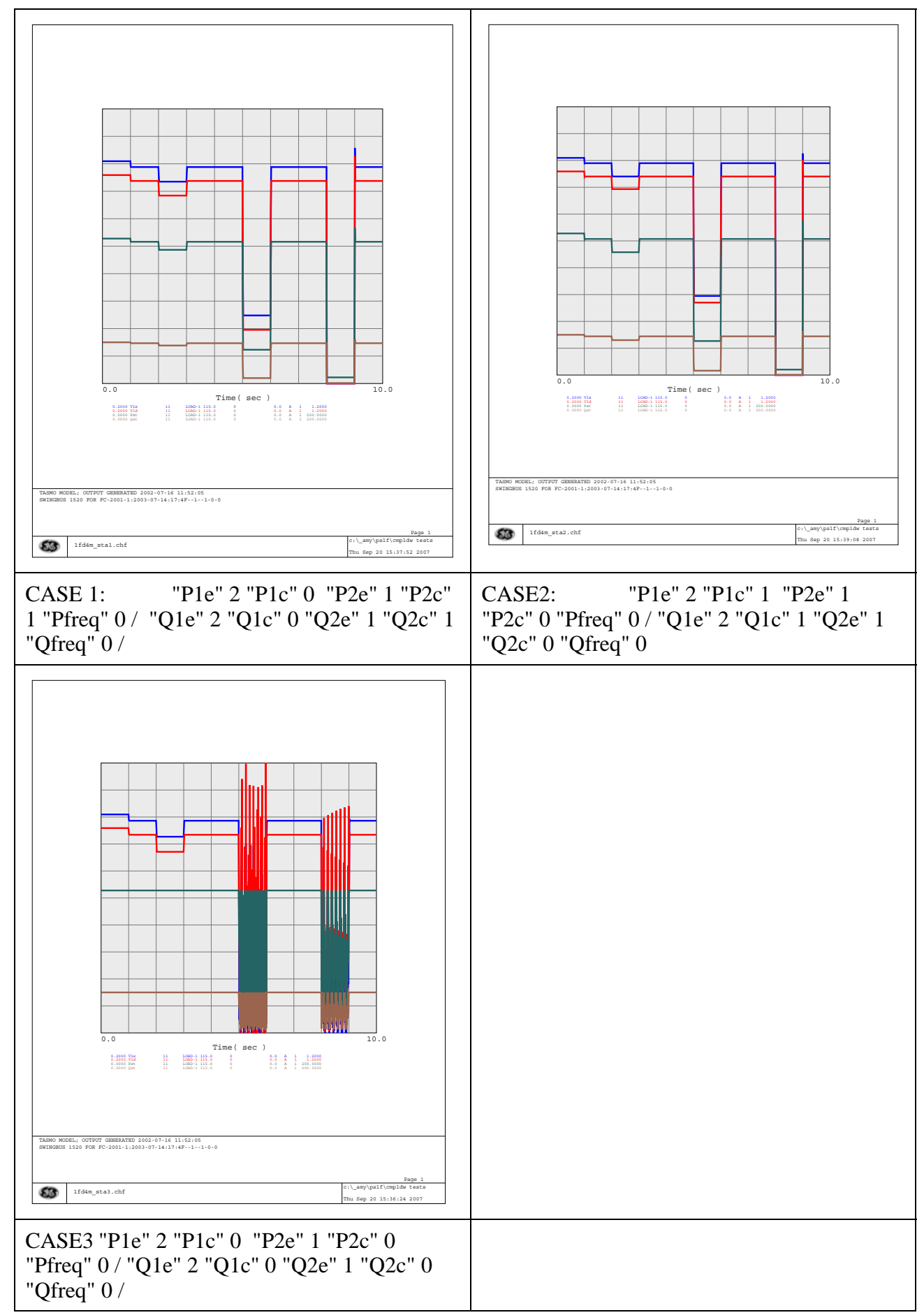




\section{Appendix III - Four Motor Dynamic Simulations}


MA: $\mathrm{HA}=0.6$, etrq $\mathrm{A}=0$

MB: $\mathrm{HB}=0.4$, etrqB $=0$

$\mathrm{MC}: \mathrm{HC}=0.2$, etrqC $=0$

$\mathrm{MD}: \mathrm{HD}=0.05$, etrqD $=0$
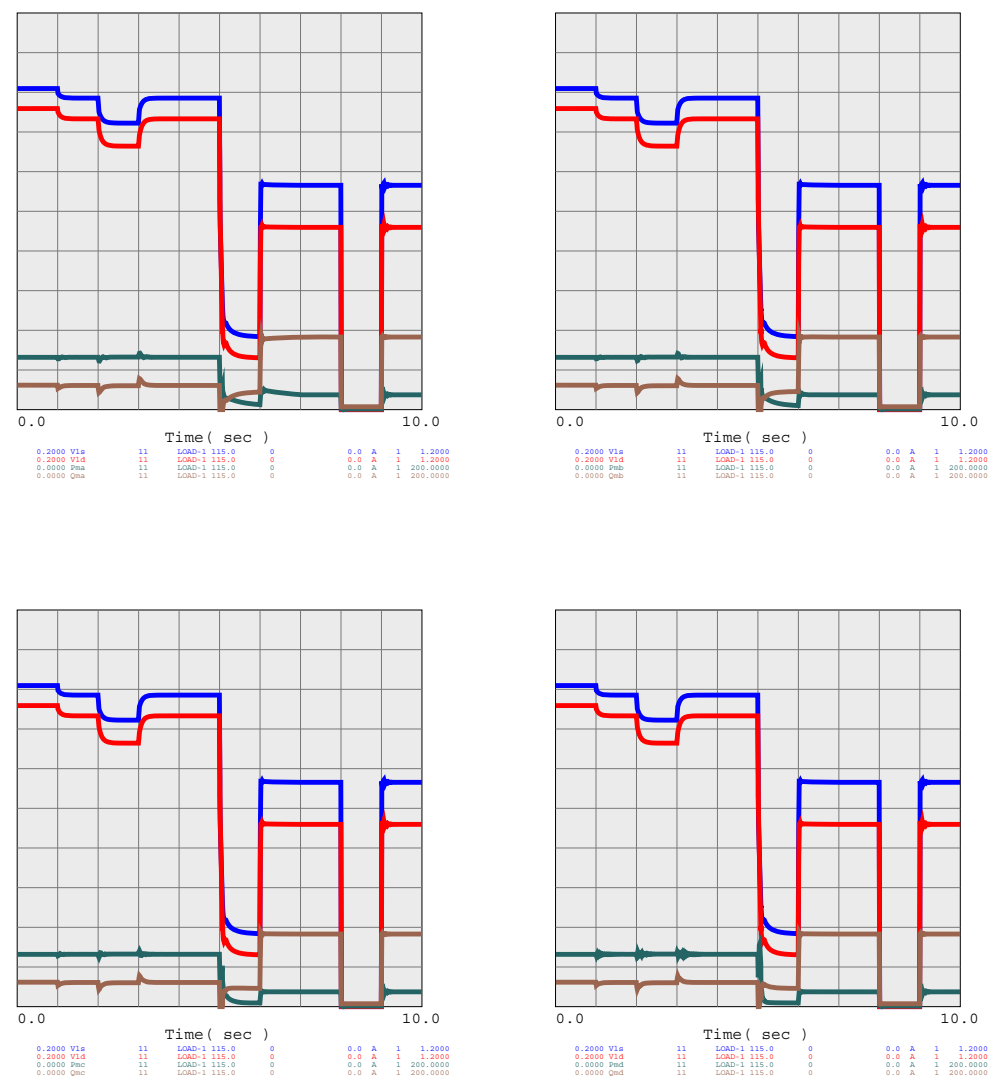

TASMO MODEL; OUTPUT GENERATED 2002-07-16 11:52:05

SWINGBUS 1520 FOR FC-2001-1:2003-07-14:17:4F--1--1-0-0

Page 1 
MA: $\mathrm{HA}=0.6$, etrqA $=2$

MB: $\mathrm{HB}=0.4$, etrqB $=2$

$\mathrm{MC}: \mathrm{HC}=0.2$, etrqC $=2$

MD: $\mathrm{HD}=0.05$, etrqD $=2$
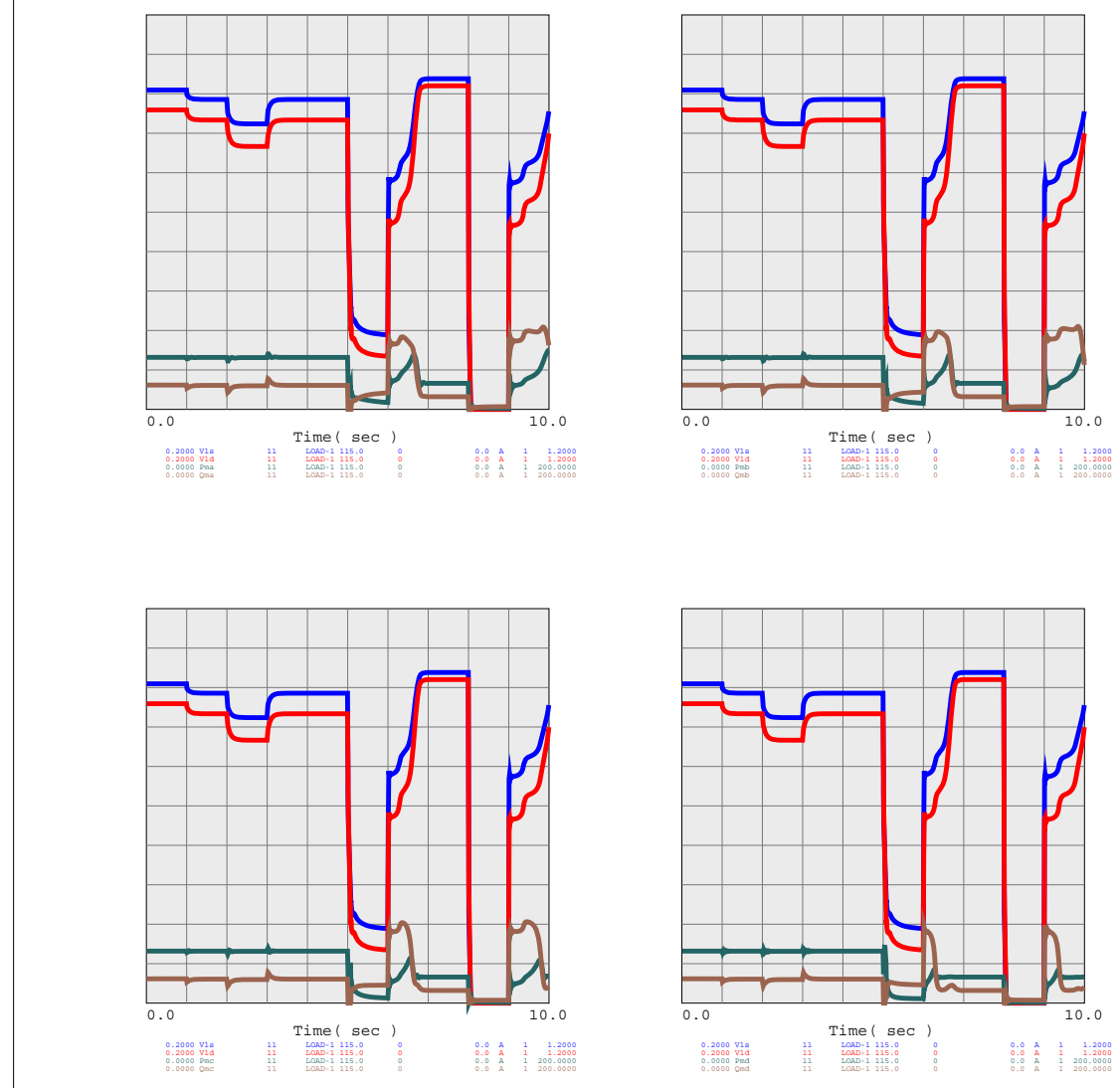

TASMO MODEL; OUTPUT GENERATED 2002-07-16 11:52:05

SWINGBUS 1520 FOR FC-2001-1:2003-07-14:17:4F--1--1-0-0

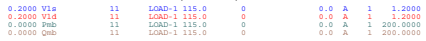

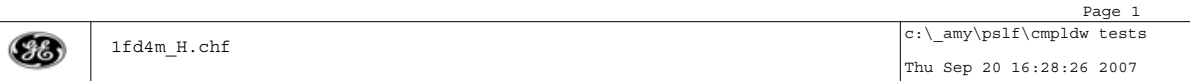


MA: $\mathrm{HA}=0.3$, etrq $\mathrm{A}=2$

MB: $\mathrm{HB}=0.3$, etrqB $=1$

MC: $\mathrm{HC}=0.3$, etrqC $=0.5$

$\mathrm{MD}: \mathrm{HD}=0.3$, etrqD $=0$
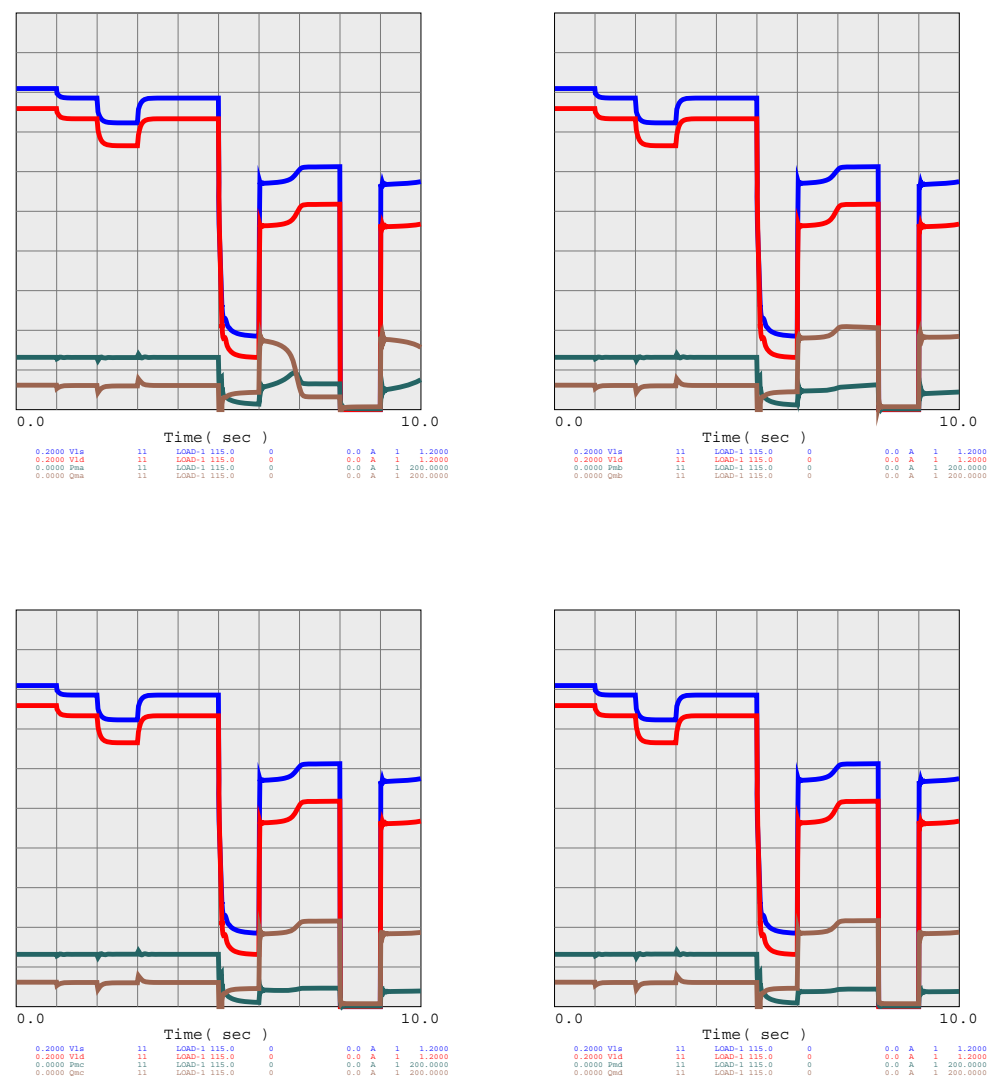

TASMO MODEL; OUTPUT GENERATED 2002-07-16 11:52:05

SWINGBUS 1520 FOR FC-2001-1:2003-07-14:17:4F--1--1-0-0 
MA: RsA $=0.0113$

MB: $\mathrm{RsB}=0.015$

MC: $\mathrm{RsC}=0.025$

MD: $\mathrm{RsD}=0.053$

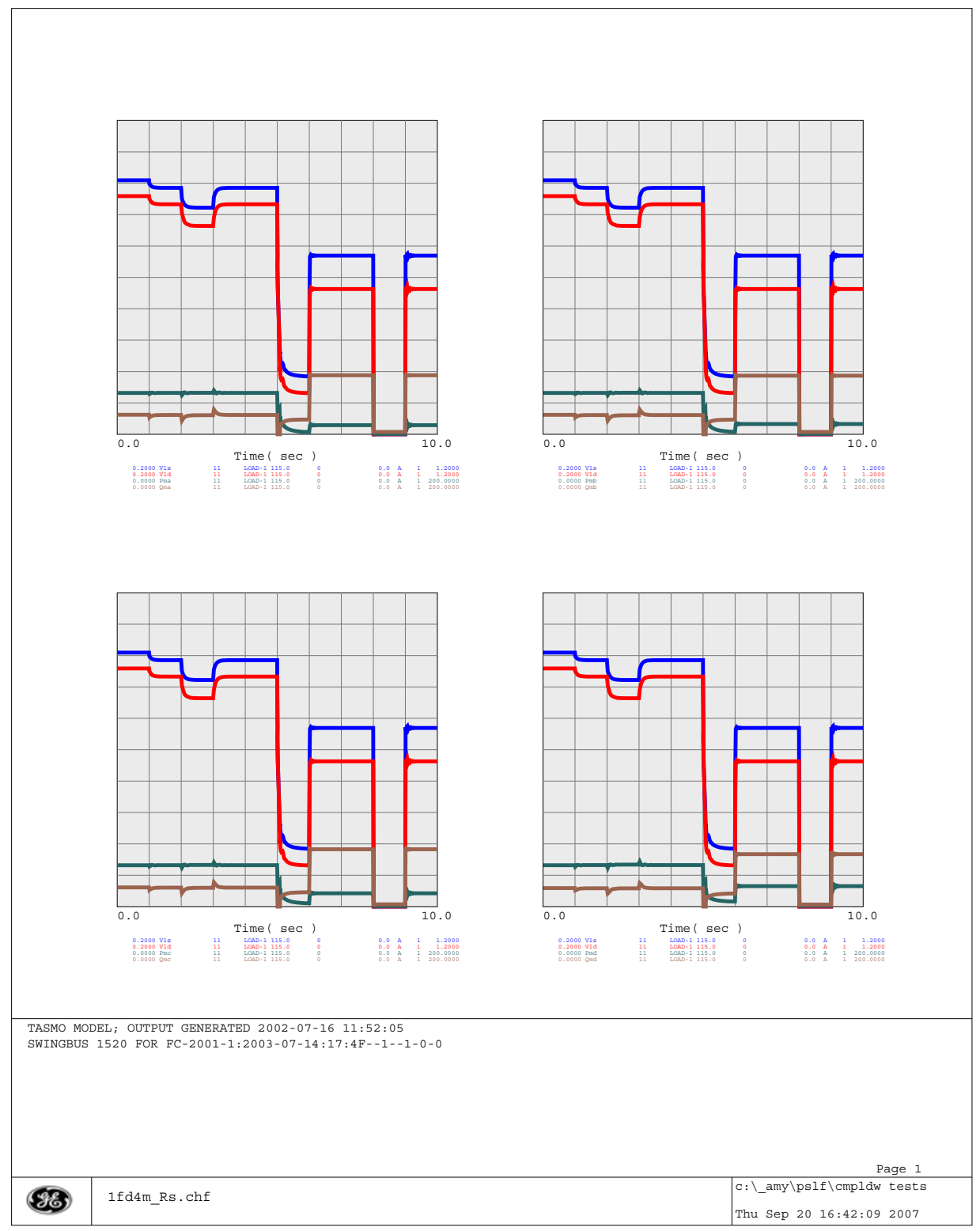


MA: Fma $=0.5$

MB: $F m b=0.3$

MC: Fmc $=0.15$

MD: Fmd=0.05

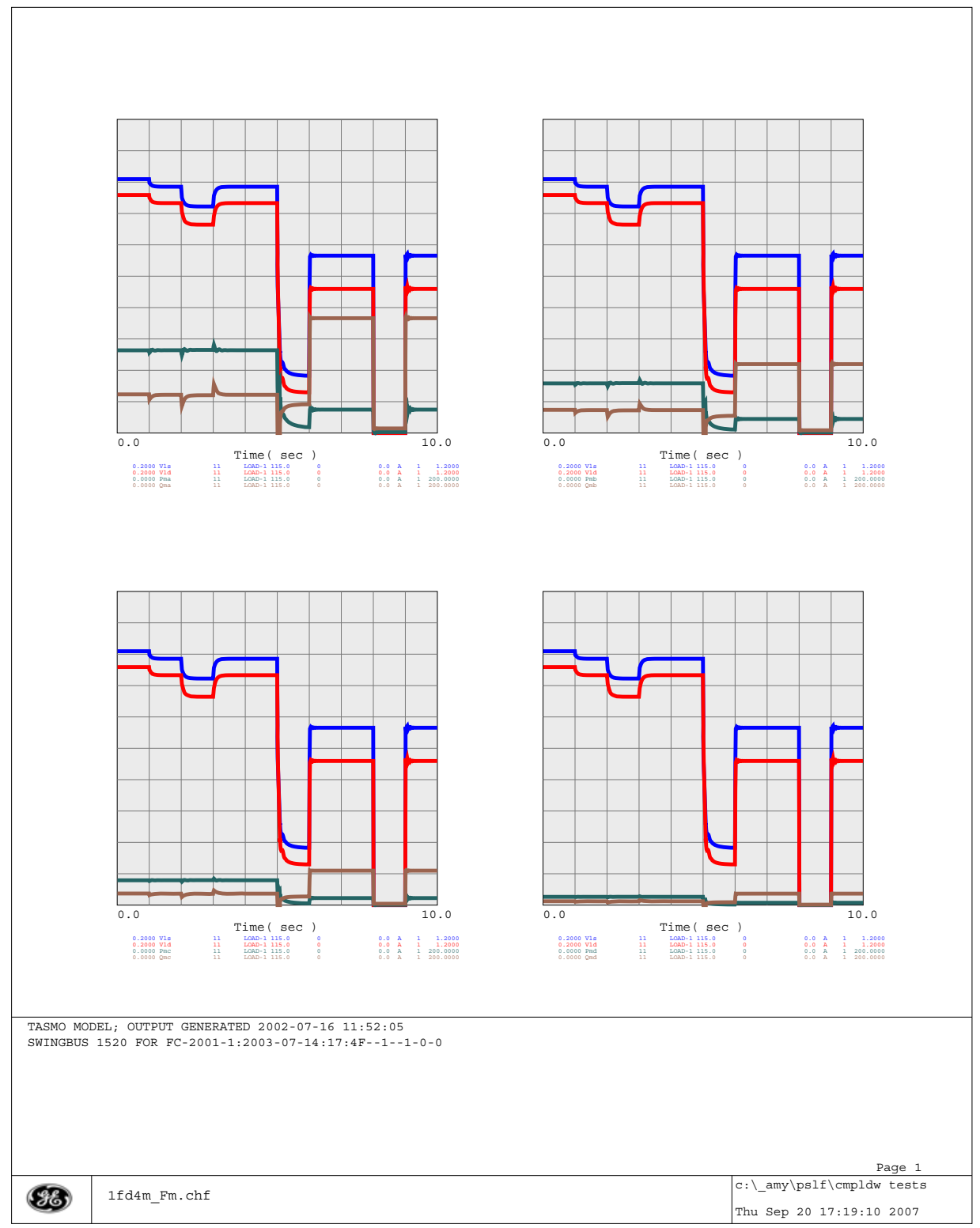


MA: Vtr2A $=0.9$

MB: Vtr2B=0.6

MC: $\operatorname{Vtr} 2 \mathrm{C}=0.3$

MD: $\operatorname{Vtr} 2 \mathrm{D}=0.1$

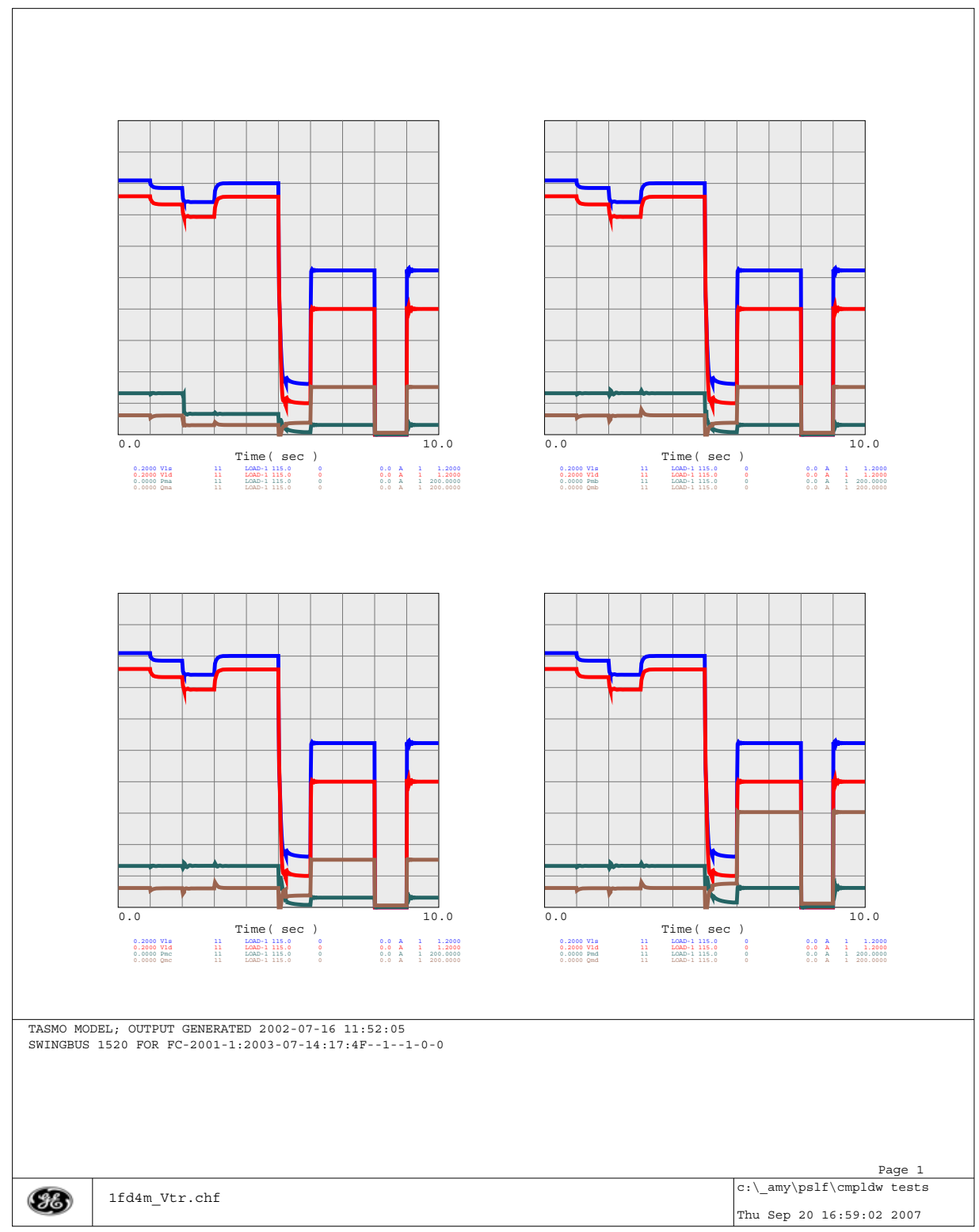


MA: Ftr2A $=0.9$

MB: Ftr2B $=0.6$

MC: Ftr2C $=0.3$

MD: Ftr2D=0.1
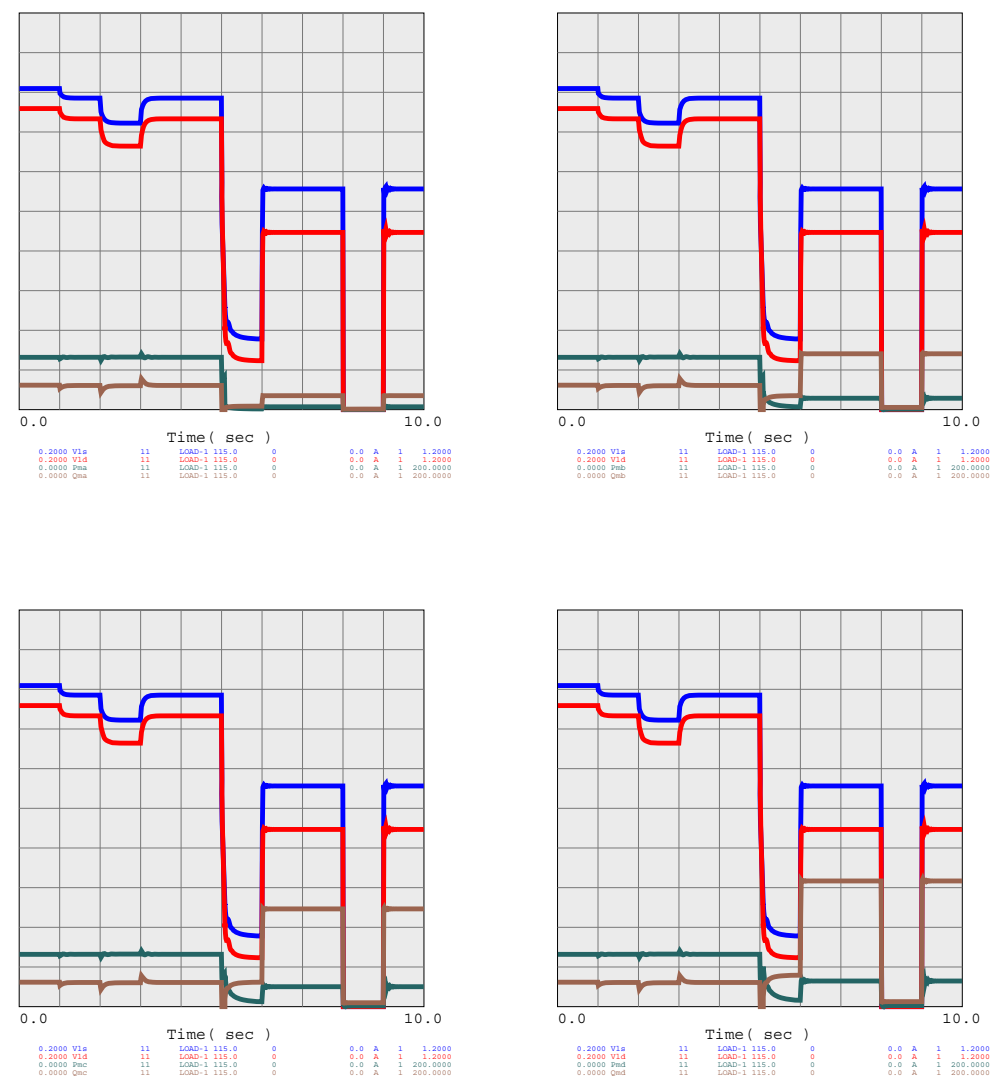

TASMO MODEL; OUTPUT GENERATED 2002-07-16 11:52:05

SWINGBUS 1520 FOR FC-2001-1:2003-07-14:17:4F--1--1-0-0 
MA: $V \operatorname{tr} 1 \mathrm{~A}=0.9, \operatorname{Ttr} 1 \mathrm{~A}=2$

MB: $V \operatorname{tr} 1 \mathrm{~B}=0.6, \operatorname{Ttr} 1 \mathrm{~B}=2$

MC: $\mathrm{Vtr} 1 \mathrm{C}=0.3, \operatorname{Ttr} 1 \mathrm{C}=2$

MD: $\mathrm{Vtr} 1 \mathrm{D}=0.1, \mathrm{Ttr} 1 \mathrm{D}=2$
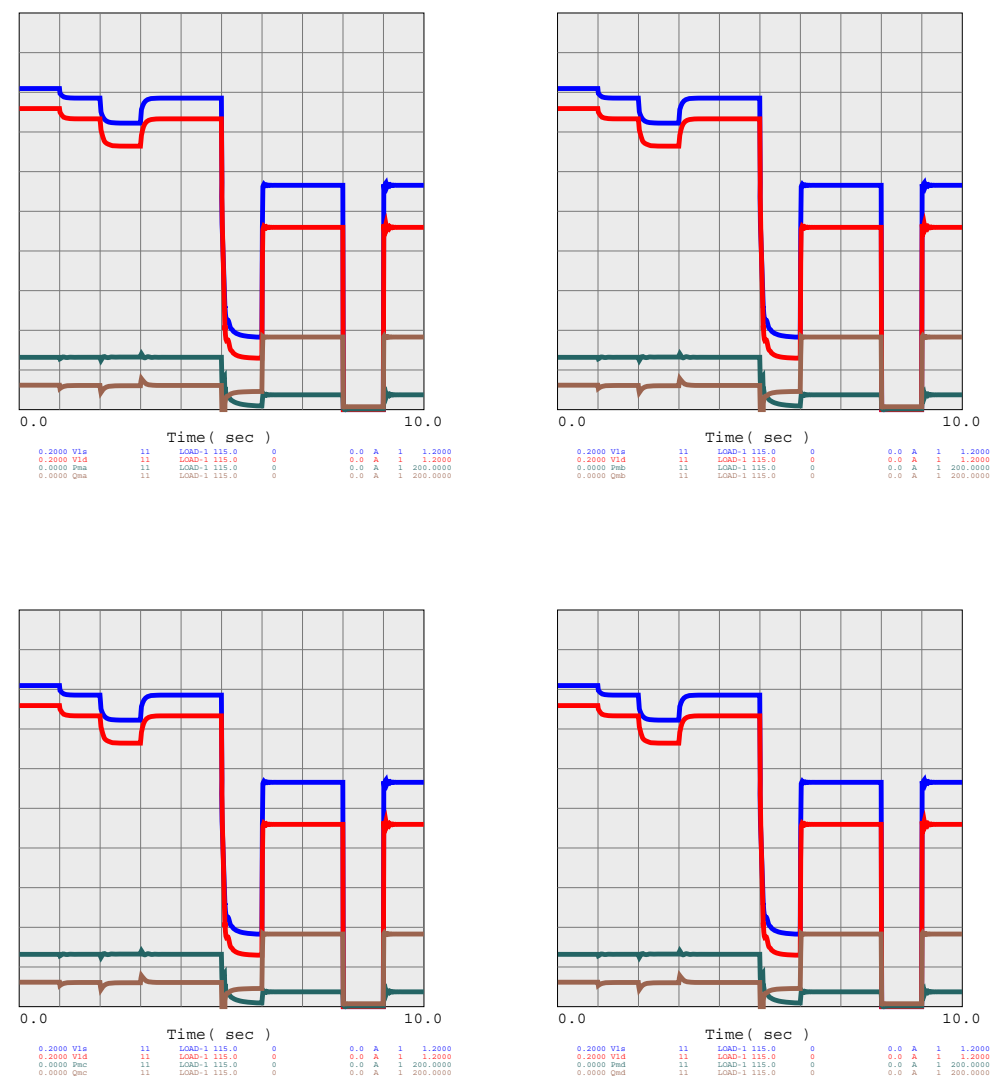

TASMO MODEL; OUTPUT GENERATED 2002-07-16 11:52:05

SWINGBUS 1520 FOR FC-2001-1:2003-07-14:17:4F--1--1-0-0 


\section{Appendix IV - One motor plus one static load}




\section{Voltage Sags}

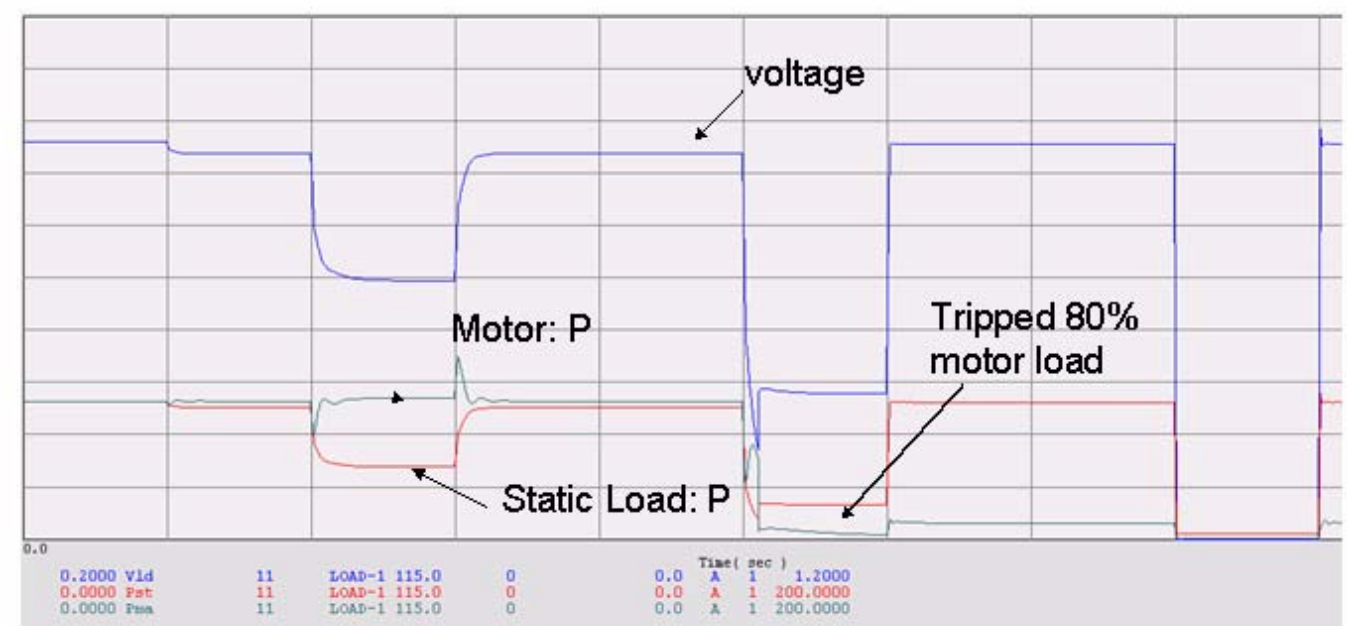




\section{Appendix V - WECC Composite Load Model (CMPLDW) Specifications}


WECC Composite Load Model (CMPLDW) Specifications

By Bill Price, GE Energy

June 8, 2007

- Changes from previous (Feb. 8) specification version are in red.

- Features that are not yet implemented in PSLF V16.1 are in green.

- Overall Specifications

- The overall structure of the CMPLDW model is shown in Figure 1.

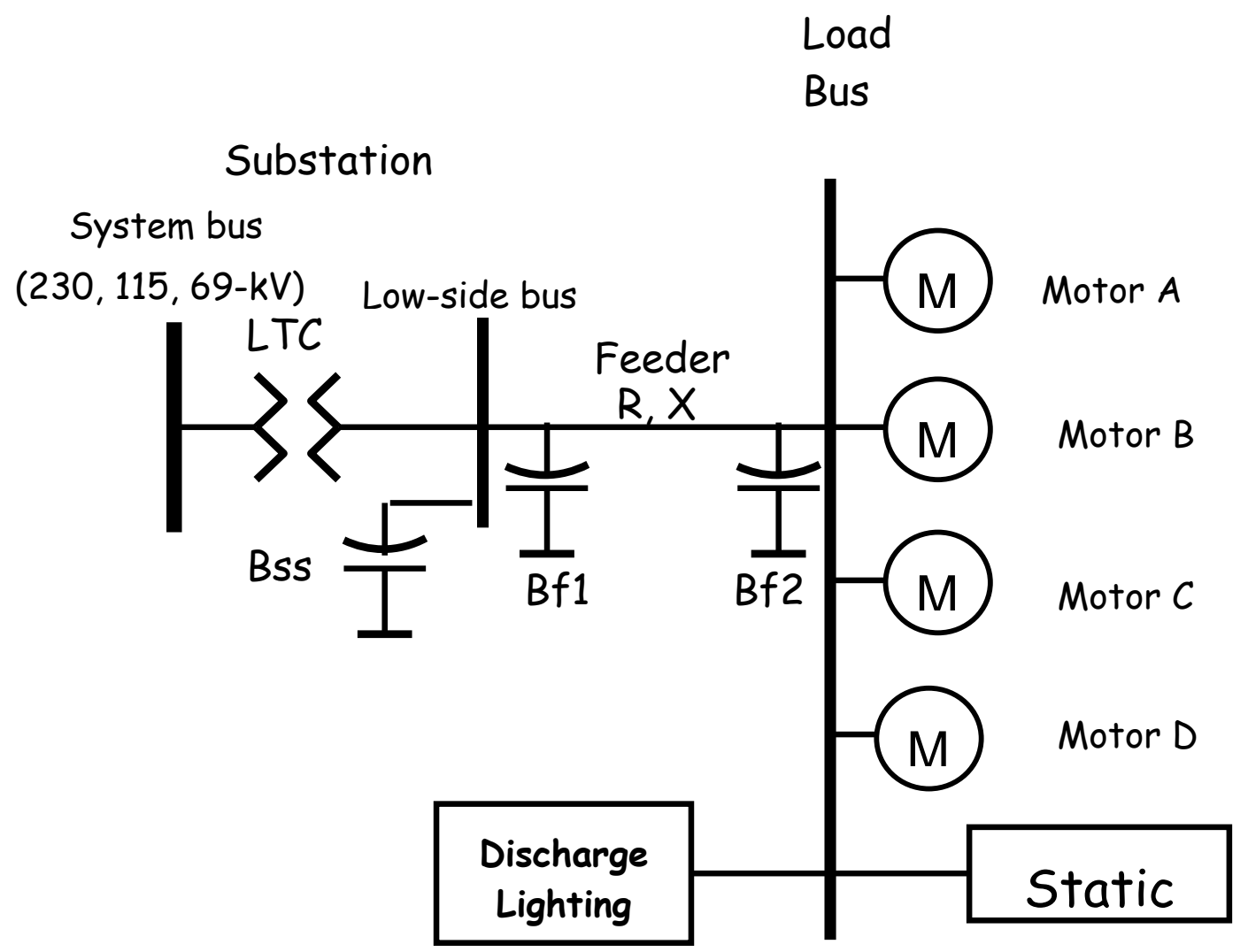

Figure 1 CMPLDW Model Structure

- Any load can be represented in dynamic simulations by a CMPLDW model. All of the $\mathbf{P}$ and $\mathrm{Q}$ of the load will be included in the CMPLDW model. 
- Fractions of the load can be tripped by relay action via the load shed signal. Such tripping will simulate tripping an equivalent amount of aggregate feeder and of each load element, but not the substation transformer or capacitor (Bss).

- Static Load Model equations:

$$
\begin{aligned}
& \mathrm{P}=\mathrm{Po} *\left(\mathrm{P} 1 \mathrm{c} * \mathrm{~V} / \mathrm{Vo}^{\mathrm{P} 1 \mathrm{e}}+\mathrm{P} 2 \mathrm{c} * \mathrm{~V} / \mathrm{Vo}{ }^{\mathrm{P} 2 \mathrm{e}}+\mathrm{P} 3\right) *(1+\mathrm{Pf} * \Delta \mathrm{f}) \\
& \mathrm{Q}=\mathrm{Qo} *\left(\mathrm{Q} 1 \mathrm{c} * \mathrm{~V} / \mathrm{Vo}^{\mathrm{Q} 1 \mathrm{e}}+\mathrm{Q} \mathrm{C} * \mathrm{~V} / \mathrm{Vo}^{{ }^{2 \mathrm{e}}}+\mathrm{Q} 3\right) *(1+\mathrm{Qf} * \Delta \mathrm{f}) \\
& \text { Po }=\text { Pload (1. - Fma }- \text { Fmb }- \text { Fmc }- \text { Fmd) } \\
& \mathrm{Qo}=\mathrm{Po} * \tan (\operatorname{acos}(\mathrm{PFs}))=\mathrm{Po} * \operatorname{Sqrt}\left(\mathrm{PFs}^{-2}-1 .\right) \\
& P 3=1 .-P 1 C-P 2 C \\
& \mathrm{Q} 3=1 .-\mathrm{Q} 1 \mathrm{c}-\mathrm{Q} 2 \mathrm{C}
\end{aligned}
$$

Convert to constant G, B below specified V (solpar.vlbrk)

- Motor Mechanical Load Model:

$$
\begin{aligned}
& \operatorname{Tm}=\operatorname{Tmo} *\left(\mathbf{a} * \omega^{2}+\mathbf{b} * \boldsymbol{\omega}+\mathbf{c}+\mathbf{d} * \omega^{\mathbf{e}}\right) \\
& \quad \mathbf{c}=\mathbf{1} . \mathbf{- a}-\mathbf{b}-\mathbf{d} \\
& \text { [WWP - Suggest replacing with Pm }=\text { Pmo } * \omega^{\mathrm{e}} \text { for consistency with } \\
& \text { motorw and fewer input parameters.] }
\end{aligned}
$$

- Shunt capacitance - The feeder capacitors (Bf1 and Bf2) will be computed during initialization of the dynamic simulation to produce the total $Q$ at the system bus. Calculation of Bf1 uses input parameter $\mathrm{fb}$ (fraction of $\mathrm{B}$ at substation) based on assumed motor power factor of 0.8. After motor initialization, $\mathrm{Bf2}$ is set to remaining required $B$.

- If LTC data is present for substation transformer, initial tap is set to put low side voltage approximately in middle of Vmin to Vmax range.

- For each composite load model, input data will be:

- Location - bus number, (name, kV), load ID

- $M V A=x x x-$ feeder \& xfmr MVA base

- if $x x x>0 ., x x x$ is the MVA base.

- if $x x x<0$, abs. value = loading factor $=$ load MW / MVA base

- if $x x x=0$., loading factor = default value (0.8)

- Bss - Substation shunt B (pu of MVA base)

- Feeder

- Rfdr - Feeder R (pu of MVA base) 
- Xfdr - Feeder X (pu of MVA base)

- Fb-fraction of feeder reactive compensation applied at the substation end of the feeder

If $X f d r=0$., feeder is omitted, but feeder capacitor is included.

- Substation transformer

If ( $x x f>$ jumper threshold), include the following:

- Xxf - transformer reactiance - p.u. of Xfmr MVA base

- Tfixhs - High-side fixed $x f m r$ tap

- Tfixls - Low-side fixed xfmr tap

- $\quad$ LTC - LTC flag - (1=active; $0=$ inactive)

- Tmin - LTC min tap (on low side)

- Tmax - LTC max tap (on low side)

- Step - LTC Tstep (on low side)

- Vmin - LTC Vmin (low side pu)

- Vmax - LTC Vmax (low side pu)

- Tdel - LTC Control time delay (sec.)

- Ttap - LTC Tap adjustment time delay (sec.)

- Rcmp - LTC Rcomp (pu of Xfmr MVA base)

- Xcmp - LTC Xcomp (pu of Xfmr MVA base)

- Load composition

- Fma-Motor A fraction

- Fmb-Motor B fraction

- Fmc-Motor C fraction

- Fmd-Motor D fraction

- Fdl - Discharge Lighting fraction

- NOTE: If sum <1., remainder is static load; if sum >1, fractions are nomalized to 1 . and there will be no static load.

- Static load parameters

- PFs - Power factor

- Ple - P1 exponent

- P1c-P1 coefficient

- P2e-P2 exponent

- P2c-P2 coefficient

- Pfrq - frequency sensitivity

- Q1e-Q1 exponent

- Q1C-Q1 coefficient

- Q2e-Q2 exponent

- Q2c-Q2 coefficient

- Qfrq - frequency sensitivity

- Motor A parameters (omit if Motor A fraction = 0.) 
- Motor B parameters (omit if Motor B fraction = 0.)

- Motor $C$ parameters (omit if Motor C fraction = 0.)

- Motor $D$ parameters (omit if Motor $D$ fraction $=0$.)

- For each motor $(x)$ that has positive fraction:

- Mtypx - Motor type (3=3-phase; $1=$ single-phase non-restarting; $2=$ singlephase restarting)

- LFmx - Loading factor (MW / MVA rating)

- $R a$

- Lsx

- Lpx

- Lppx

- Tpox

- Tppox

- $\mathrm{Hx}$

- atrqx Torque coeff. for $w^{2}$

- btrqx Torque coeff. for w

- dtrqx Torque coeff. for $w^{e}$

- etrqx Torque speed exponent

- Vtr1x - U/V Trip1 V (pu)

- Ttr1x - U/V Trip1 Time (sec)

- Ftr1x-U/V Trip1 fraction

- Vrc1x-U/V Trip1 reclose V (pu)

- Trc1x-U/V Trip1 reclose Time (sec)

- Vtr2x - U/V Trip2 V (pu)

- Ttr2x - U/V Trip2 Time (sec)

- Ftr2x - U/V Trip2 fraction

- Vrc2x - U/V Trip2 reclose V (pu)

- Trc2x - U/V Trip2 reclose Time (sec)

- NOTE: Reclosing a partially tripped motor will add tripped portion but will not model restarting; Reclosing a fully tripped motor will model restarting.

- If motor type =1: [Details may change]

Vstx - Stall voltage (pu)

Gstx - Stall G (pu of motor MVA rating)

Bstx - Stall B (pu of motor MVA rating)

I2tx - Trip level after stall - Integral of $I^{2}(?)$ (pu $I^{2}$-sec)

- If motor type = 2: [Details may change]

Vstx - Stall voltage (pu)

Gstx - Stall G (pu of motor MVA rating)

Bstx - Stall B (pu of motor MVA rating)

Vrstx - Restart voltage (pu) 


\section{Sample dyd records:}

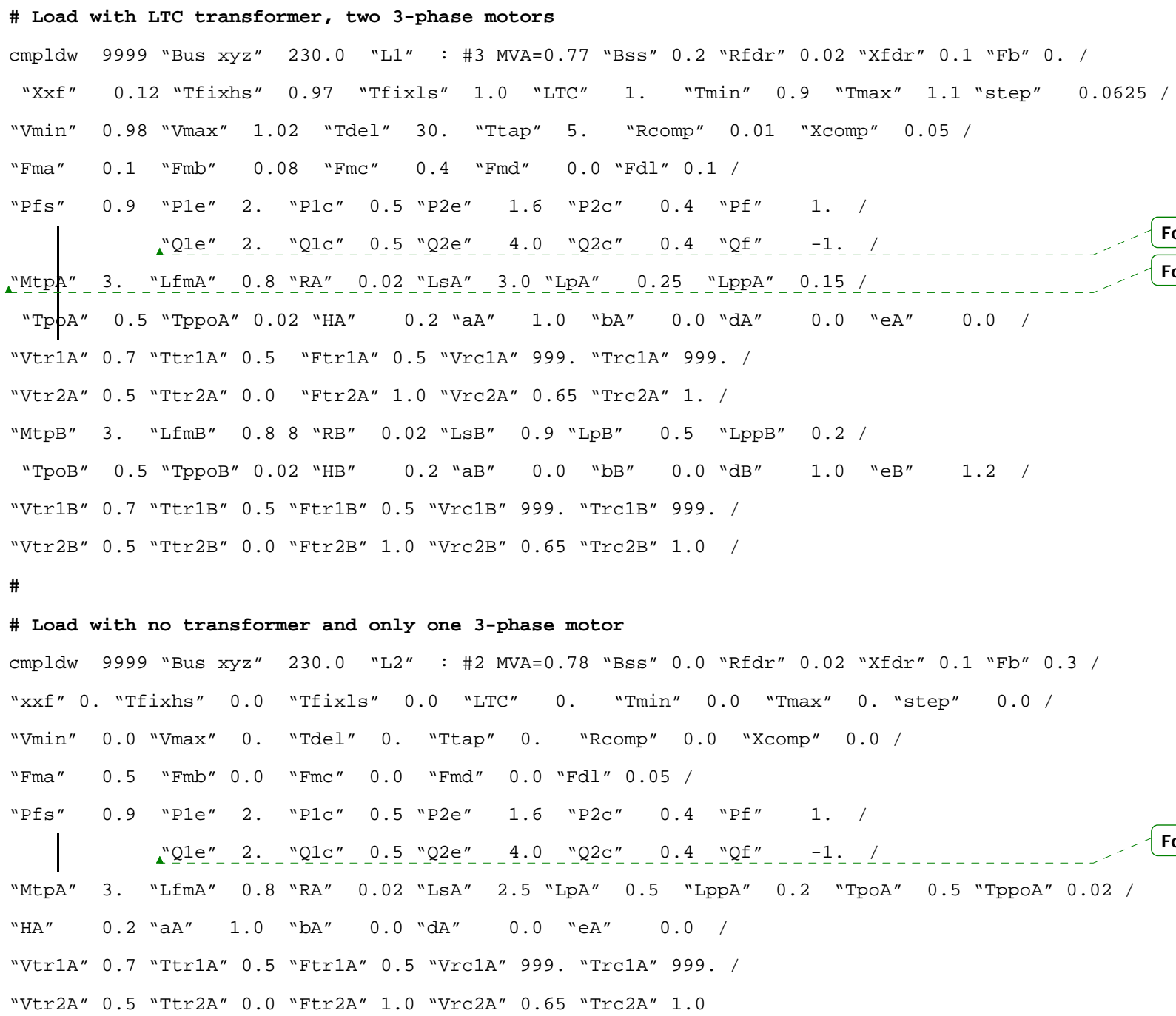


- Output variables will be:

- Level 1

- PId - Total MW at system bus

- Qld - Total MVAr at system bus

- Level 2

- Vls - pu voltage at substation low-side bus

- Vld - pu voltage at load end of feeder

- Level 3

- Pst-Static load component MW

- Qst - Static load component MVAr

- Pma-Motor A MW

- Qma-Motor A MVAr

- Pmb - Motor B MW

- Qmb-Motor B MVAr

- Pmc-Motor CMW

- Qmc-Motor C MVAr

- Pmd - Motor D MW

- Qmd - Motor D MVAr

- Pdl - Discharge lighting load MW

- Qdl - Discharge lighting load MVAr

- Level 4

- spda-Motor A speed (pu)

- Tma-Motor A Current (pu)

- Tea-Motor A speed (pu)

- spdb - Motor B speed (pu)

- Tmb - Motor B Current (pu)

- Teb-Motor B speed (pu)

- spdc-Motor C speed (pu)

- Tmc-Motor C Current (pu)

- Tec-Motor C speed (pu)

- spdd - Motor D speed (pu)

- Tmd - Motor D Current (pu)

- Ted-Motor D speed (pu)

- Level 5

- Fma - fraction of Motor A in operation

- Fmb - fraction of Motor B in operation

- Fmc - fraction of Motor C in operation

- Fmd - fraction of Motor D in operation

- Include "metering" models

- Total CMPLDW outputs for zone, area, and whole system 


\section{- Initialization process:}

1. Get total load $P \& Q$, system bus $V$ from load flow

2. Add low-side bus and load bus to Ymatrix

3. Add $x$ fmr, feeder, and substation cap. (Bss) to Y matrix

4. Compute low-side bus voltage.

5. Adjust LTC tap to put low-side voltage near midpoint of range.

6. Estimate feeder shunt (Bf) requirement using static load $Q$ and estimated motor $Q$ (based on 0.8 power factor).

7. If $B f<0$. (inductive), reduce $B s s$ to make $B f=0$.

8. Set $B f 1=F b * B f$.

9. Compute far-end bus voltage.

10. If far-end voltage is less than 0.95 p.u., or greater than 1.05 p.u., modify feeder $X$ to bring within range. Adjust $R$ to maintain same $X / R$ ratio.

11. Compute required far-end $P$ and $Q$ to match system bus $P$ and $Q$ accounting for losses in transformer, feeder, and shunts.

12. Initialize motor models and static load models - obtain total $Q$ of load components.

13. Set $B f 2$ to match required $Q$ at far-end bus.

\section{- Calculations during normal running:}

- sorc mode: (before network solution)

- Use low-side voltage, load voltage, and frequency from previous network solution

- Compute current injection at load (far end) bus from motor and static load models.

- If LTC tap has changed, compute current injections at system and low-side buses to reflect tap change. (Present logic changes tap and refactorizes $Y$ matrix.)

- netw mode: (iteration with network solution)

- Update current injection at load bus from motor and static load models based on change in load bus voltage.

- alge mode: (after network solution)

- Check for tripping conditions and modify models as required

- rate mode: (diff. equation update)

- Update derivatives of state variables in motor models 